\title{
EUGENOL ATTENUATES FORMALDEHYDE INDUCED LIVER DAMAGE IN ADULT WISTAR RATS
}

1* Uthman Ademola Yusuf, ${ }^{2}$ Mesole Bolaji Samuel, ${ }^{3} T o s i n$ J Kolawole, 1John Amos Mulemena, 'Kingsley

Kamvuma, ${ }^{4}$ Olugbenga Olawale Eweoya, ${ }^{2}$ Michelo Haluuma Miyoba and ${ }^{5}$ Tirimisiyu Alani Ogunola,

1. Department of Anatomy, School of Medicine and Health Sciences, Mulungushi University, Livingstone Campus, Zambia.

2. Department of Medicine, School of Medicine and Health Sciences, Eden University, Lusaka, Zambia.

3. Department of Anatomy, Faculty of Basic Medical Sciences, Ahmadu Bello University, Zaria, Nigeria

4. Department of Anatomical Sciences, University of Abuja. Nigeria.

5. Department of Chemical Pathology, Ladoke Akintola University of Technology Teaching Hospital, Ogbomoso. Nigeria.

Email: uthmanademola@yahoo.com

\section{ABSTRACT}

Formaldehyde (FA) has over the years been linked has been linked to oxidative stress and has the ability to increase and over time elevate liver enzymes which would result in hepatotoxicity. However paucity of data with regards to the protective effects of eugenol on FA induced toxicity. This study was aimed at investigating the effect of eugenol on FA induced toxicity. A total of 24 adult Wistar rats was divided into four (4) groups. Group I was administered $1 \mathrm{mg} / \mathrm{kg}$ bwt of distilled water (control), Group II was administered $150 \mathrm{mg} / \mathrm{kg}$ bwt Eugenol, Group III was administered $5 \mathrm{mg} / \mathrm{kg}$ bwt of FA, and Group IV was coadministered $5 \mathrm{mg} / \mathrm{kg} F A$ and $150 \mathrm{mg} / \mathrm{kg}$ bwt of eugenol for a duration of 14 days. Rats were humanely sacrificed with a dose of $0.8 \mathrm{mg} / \mathrm{kg}$ bwt ketamine anaesthesia which was administered intraperitoneally. Liver tissues was used to assay for biochemical parameters such as Aspartate aminotransferase (AST), Alanine transaminase(ALT), Superoxide dismutase (SOD), Glutathione Perioxidase (GPX), Malondialdehyde (MDA), Nitric oxide (NO). Administration of FA resulted in a significant $(p<0.05)$ increase in AST, ALT, NO, MDA and significant $(p<0.05)$ reduction in GPx and SOD tissue activity However coadministration of Eugenol and formaldehyde resulted in significant $(p<0.05)$ reduction in tissue levels of AST, ALT, NO MDA and significant $(p<0.05)$ increase in tissue activity of GPX and SOD activity. Results obtained from this study indicated that eugenol is efficacious at preventing oxidative damage induced by FA administration.

Keywords: Melatonin, Formaldehyde, Superoxide dismutase, Nitric oxide, Alanine transaminase Malondialdehyde, Oxidative stress 


\section{Introduction}

Formaldehyde (FA) is a very prevalent hydrophilic compound that is absorbed but not limited through the lungs and gastrointestinal tract and to a very little extent the skin and eyes. Exposure to FA are very pronounced through the eyes, nose, skin and throat $[1,2]$. Some individuals can become symptomatic when they are exposed to very low levels of FA. Some individuals can experience mild uneasiness and some show mild to no symptoms at low levels of exposure. Average level of exposure to $\mathrm{FA}$ is at the highest level in the Human Anatomy dissection room or in a morgue that makes use of Formaldehyde for embalming [3].

FA is a liquid which appears colorless, flammable and highly reactive at standard pressure and temperature [4]. It is broken down in the air and highly stable in liquid [5]. FA diffuses quickly into any tissue such as the liver, kidney and brain and can be absorbed through the oral or intraperitoneal route since it collaborates with various cellular components of these tissues [6]. Early usage of formalin was restricted to use as a fixative and treating liquid. However nowadays formalin is widely used more frequently and has found its way to everyday use. The most appalling use of formalin is as food additive [7] and this led to a tremendous increase in exposure to formalin. After ingestion, FA is easily absorbed into the gastrointestinal tract and via the intestinal villi into the bloodstream. However within the liver, FA is mainly metabolized into methanol and formate by aldehyde dehydrogenase I or mitochondrial aldehyde dehydrogenase $\|$, respectively. Toxic concentration of FA are very observable in hepatocytes [8]

Exposure of experimental animals reveled cytoarchitectural distortion within the gastrointestinal tract and hepatotoxicity [9]. At low dosage, FA has been proven to be carcinogenic and mutagenic and all this deleterious features can be manifested in different organs [10]. Water containing high concentration of FA has been implicated in gastrointestinal cancer [11]. Developing countries such as Nigeria, Zambia india has haphazard use of FA in most food items and water meant for drinking has exposed huge number of the population to health hazards which includes brain and liver damage [12]. The Liver is the largest organ by weight and it is very vital in the digestion of sugar, fat and proteins. Other functions include detoxicification of wastes such as ammonia. The spleen alongside the liver destroys worn-out red blood cells and the re-use of its constituents. The liver also is responsible for the synthesis and secretion of bile, lipoproteins, plasma proteins and coagulating factors. It also ensures constant blood glucose level through glycogenesis, glycogenolysis and gluconeogenesis. The liver also plays a significant role in the elimination and detoxification of drugs. Therefore, xenobiotics (for example, liquor and numerous drugs), malnutrition, infection, and anemia, can induce liver damage [13]. Hepatic damage is a common disease that mostly occurs as a result of 
oxidative stress and involves progressive growth from steatosis to hepatocellular carcinoma [14]. Eugenol as a naturally occurring component of plants such as clove, Occimum gratissimum and Ocimum sanctum. It is an established antioxidant that helps re-establish balance between pro- and anti-apoptotic proteins induced by aluminium chloride [15].

The study therefore investigated the hepatoprotective effect of eugenol on FA induced toxicity, and hence aimed at obtaining an alternative therapeutic potential with minimal side effects.

\section{Materials and Methods}

A total of twenty four adult Wistar rats with an average weight of $150-160 \mathrm{~g}$ and obtained from the animal house of Mulungushi University Livingstone, Zambia, were allowed to free access to food and water ad libitum. This research was approved by Mulungushi University School of medicine research ethics committee. Experiments were carried in accordance with the National institute of health guide for the care and use of laboratory animals [16]. All measures were put in place to significantly reduce animal suffering. Rats were divided into four (4) groups with six (6) animals in each groups. Group I was administered $1 \mathrm{mg} / \mathrm{kg}$ distil water control (CTRL); Group II was administered 150 $\mathrm{mg} / \mathrm{kg}$ eugenol (EG); Group III was coadministered $150 \mathrm{mg} / \mathrm{kg}$ eugenol and 5 $\mathrm{mg} / \mathrm{kg}$ of Formaldehyde (FA+EG); Group IV administered $5 \mathrm{mg} / \mathrm{kg}$ Formaldehyde intraperitoneally as shown in table 1.

Table1 showing animal Groupings and Dosage

\begin{tabular}{cc}
\hline Rat Groupings & Dosage \\
\hline CTRL & $1 \mathrm{mg} / \mathrm{kg}$ \\
EG & $150 \mathrm{mg} / \mathrm{kg}$ \\
FA+EG & $5 \mathrm{mg} / \mathrm{kg}+150 \mathrm{mg} / \mathrm{kg}$ \\
FA & $5 \mathrm{mg} / \mathrm{kg}$ \\
\hline
\end{tabular}

Rats were weighed at the beginning and the end of the research. FA was administered intraperitoneally, while eugenol was administered orally throughout the duration of this study 114 days). At the end of the study (24 hrs after last administration i.e day 15). Animals were humanely sacrificed using ketamine as anesthesia and injected intraperitoneally at a dose of $0.8 \mathrm{mg} / \mathrm{kg}$. The abdomen and the thorax were opened, the liver was removed and washed three times in ice cold saline and blotted on ash-free filter paper, used for preparation of tissue homogenates for estimation of tissue activity of ALT, AST, MDA, SOD, NO and GPx enzymes.

\section{Preparation of tissue homogenates}

The liver was weighed and homogenized separately with a potter- Elvenhjem tissue homogenizer The liver was homogenized in phosphate buffer saline (PBS) $50 \mathrm{mM}$ pH 2021 January Edition |www.jbino.com | Innovative Association 
(7.4) for estimation of protein content of ALT, AST, SOD, MDA, NO and GPX. The crude tissue homogenate was centrifuged at $10,000 \mathrm{rpm}$, for 15 minutes in cold centrifuge, and the resultant supernatant was used for the different estimations. Protein content in tissue homogenate was measured according to the method of Rosenbrough et al. [17]

\section{Liver Function Test}

Tissue homogenates were used, using a standard procedure. Biomarkers of Liver Function assayed include Aspartate Aminotransferase (AST) and Alanine Aminotransferase (ALT) were both assayed using appropriate kits following manufacturer's instructions (Abcam Rat ELISA AST and ALT Kits)

\section{Oxidative Stress Markers}

Superoxide dismutase (SOD) activity was investigated with rat SOD ELISA Kit (supplied by WKEA Med Supplies Corp., China, and manufactured by Fine Test China) and used as stated by the manufacturer. The procedure was based on the method of [12] as reported by [13]. Nitric Oxide (NO) and Gluthatione Peroxidase GPx activity was measured using NO ELISA Kit (supplied by WKEA Med Supplies Corp., China, and manufactured by Fine Test china) and used as stated by the instructions of the manufacturer. The procedure was based on the method of [18]. These levels were expressed as $\mu \mathrm{mol} / \mathrm{ml}$.

\section{Data Analysis}

Results obtained from this research were analyzed with the statistical package for social sciences (IBM SPSS version 21.0, SPSS) and Microsoft Office Excel 2007 for charts. These results were expressed as of mean (SEM) and significant differences among means of the groups were determined with one-way analysis of variance (ANOVA) with Tukey's post hoc test for significance. Paired samplet-test was used for comparison of mean. Values were considered significant when $\mathrm{p} \leq 0.05$.

\section{Results}

Figure 1 shows the effect of eugenol on AST levels in the liver of Wistar rats following administration of formaldehyde. This result reveals a significant $(p<0.05)$ increase in the levels of

AST in the group administered formaldehyde (FA) when compared to the control. However co-administration of formaldehyde and eugenol (FA+EG) lead to a significant $(p<0.05)$ reduction in the levels of AST when compared to the group treated FA. 


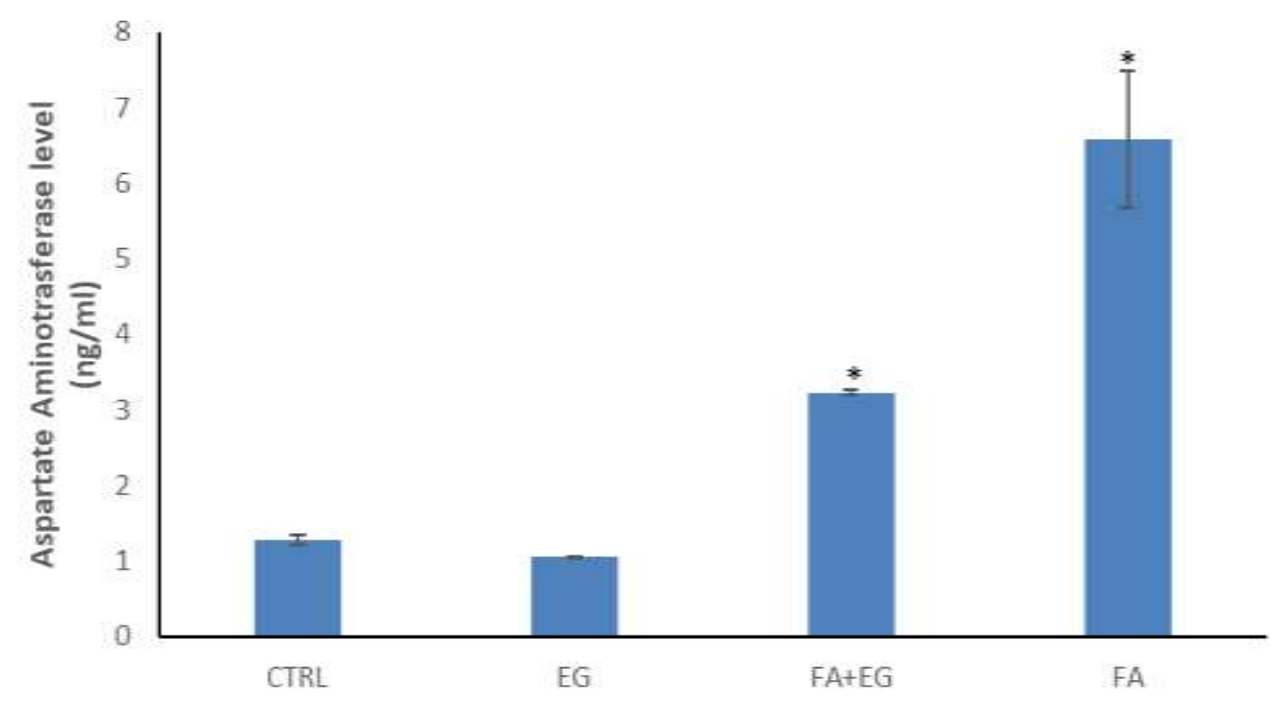

Figure 1: The Effect of Eugenol on AST levels in the liver of Wistar rats following administration of FA $\mathrm{n}=6$; mean \pm SEM One way Turkey’s post-hoc test: $*=\mathrm{p}<0.05$, when FA+EG is compared to FA group.

Figure 2 shows the effect of eugenol on ALT levels in the liver of Wistar rats following administration of formaldehyde. This result reveals a significant $(\mathrm{p}<0.05)$ increase in the levels of ALT in the group administered formaldehyde (FA) when compared to the control. However co-administration of formaldehyde and eugenol $(\mathrm{FA}+\mathrm{EG})$ lead to a significant $(\mathrm{p}<0.05)$ reduction in the levels of ALT when compared to the group treated FA.

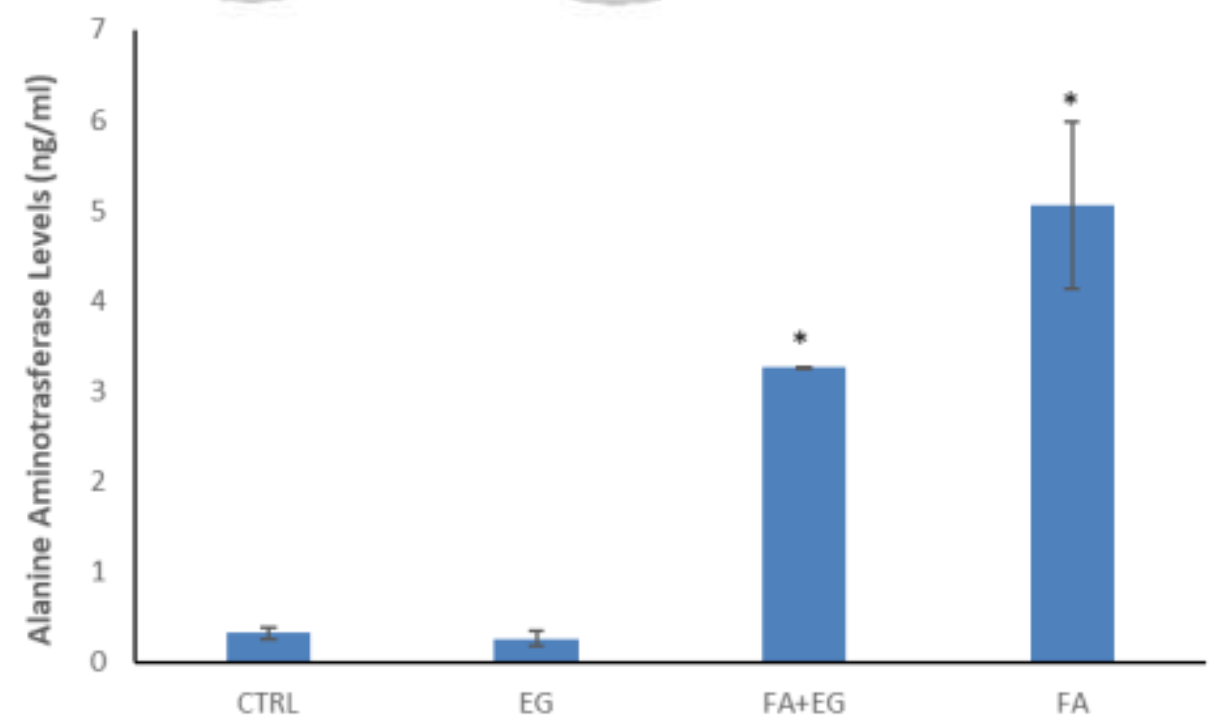

Figure 2: The Effect of Eugenol on ALT levels in the liver of Wistar rats following administration of FA $\mathrm{n}=6$; mean \pm SEM One way Turkey's post-hoc test: $*=\mathrm{p}<0.05$, when FA+EG is compared to FA group. 
Figure 3 shows the effect of eugenol on the activity of Superoxide Dismutase In the Liver of Wistar rat following the administration of formaldehyde. This result shows a significant $(\mathrm{p}<0.05)$ reduction in the activity of SOD when FA treated group is compared to the control. However administration of eugenol resulted in a significant $(\mathrm{p}<0.05)$ elevated (improved) the levels of SOD when compared to the FA treated group. The group administered eugenol (EG) only revealed an increase in tissue activity of SOD when compared to the control (CTRL)

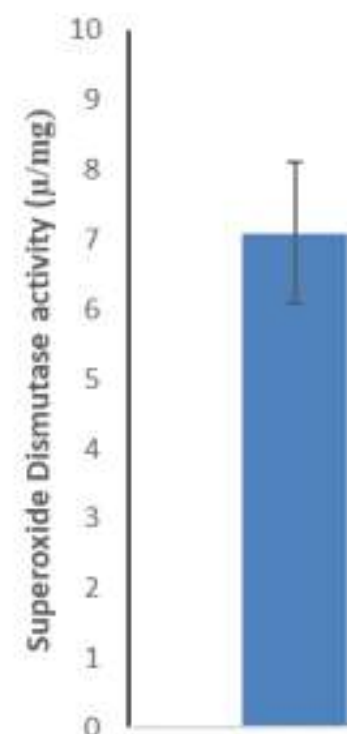

CTRL

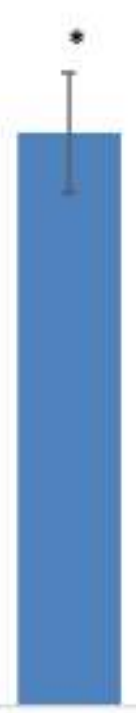

EG

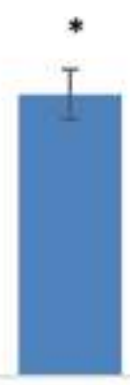

FA+EG

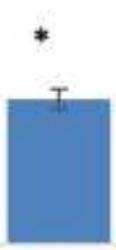

FA

Figure 3: Effect of Eugenol on Liver activity of SOD following administration of FA $\mathrm{n}=6$; mean \pm SEM One way Turkey's post-hoc test: $*=\mathrm{p}<0.05$, when FA+EG is compared to FA group and when EG is compared to control (CTRL) 
Figure 4 shows the effect of Eugenol on Glutathione Perioxidase activity in the liver of Wistar rat following the administration of FA. This result shows a significant $(\mathrm{p}<0.05)$ reduction in the activity of GPx when FA treated group is compared to the control. However co-administration of eugenol resulted in a significant $(\mathrm{p}<0.05)$ elevated (improved) the levels of GPx when compared to the FA treated group. The group administered eugenol (EG) only revealed an increase in tissue activity of GPx when compared to the control (CTRL)

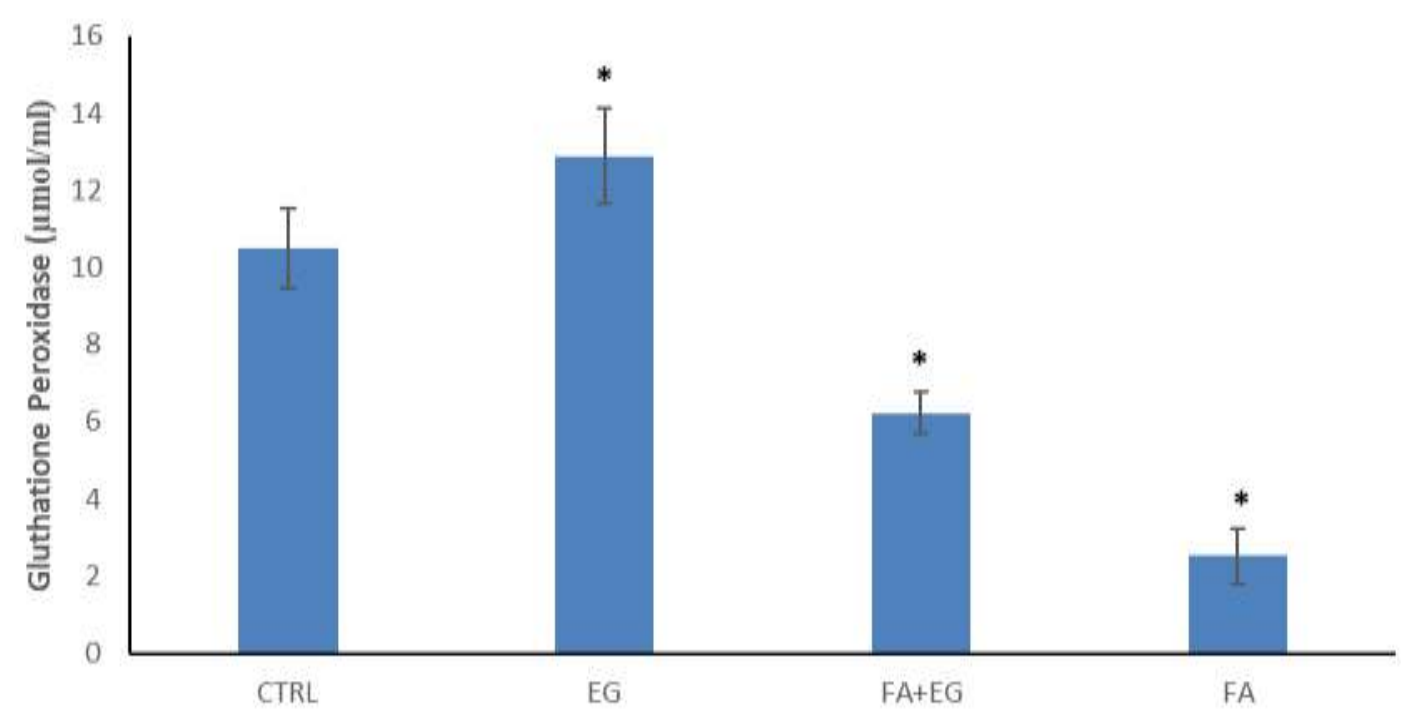

Figure 4: Effect of eugenol on the activity of GPx in the liver of Wistar rat following the administration of FA $\mathrm{n}=6$; mean \pm SEM One way Turkey's post-hoc test: $*=\mathrm{p}<0.05$, when FA+EG is compared to FA group and when EG is compared to control (CTRL) 
Figure 5 shows the effect of eugenol on the levels of nitric oxide in Wistar rats following administration of FA. This result shows a significant $(\mathrm{p}<0.05)$ increase in the activity of Nitric oxide in the group administered FA when compared to the control (CTRL). How upon co-administration of Formaldehyde and eugenol (FA+EG) there was a significant $(\mathrm{p}<0.05)$ reduction in the tissue level of Nitric oxide when compared to the the FA group. However there was no significant difference in the level of Nitric oxide of the group administered eugenol only (EG) when compared to the control (CTRL).

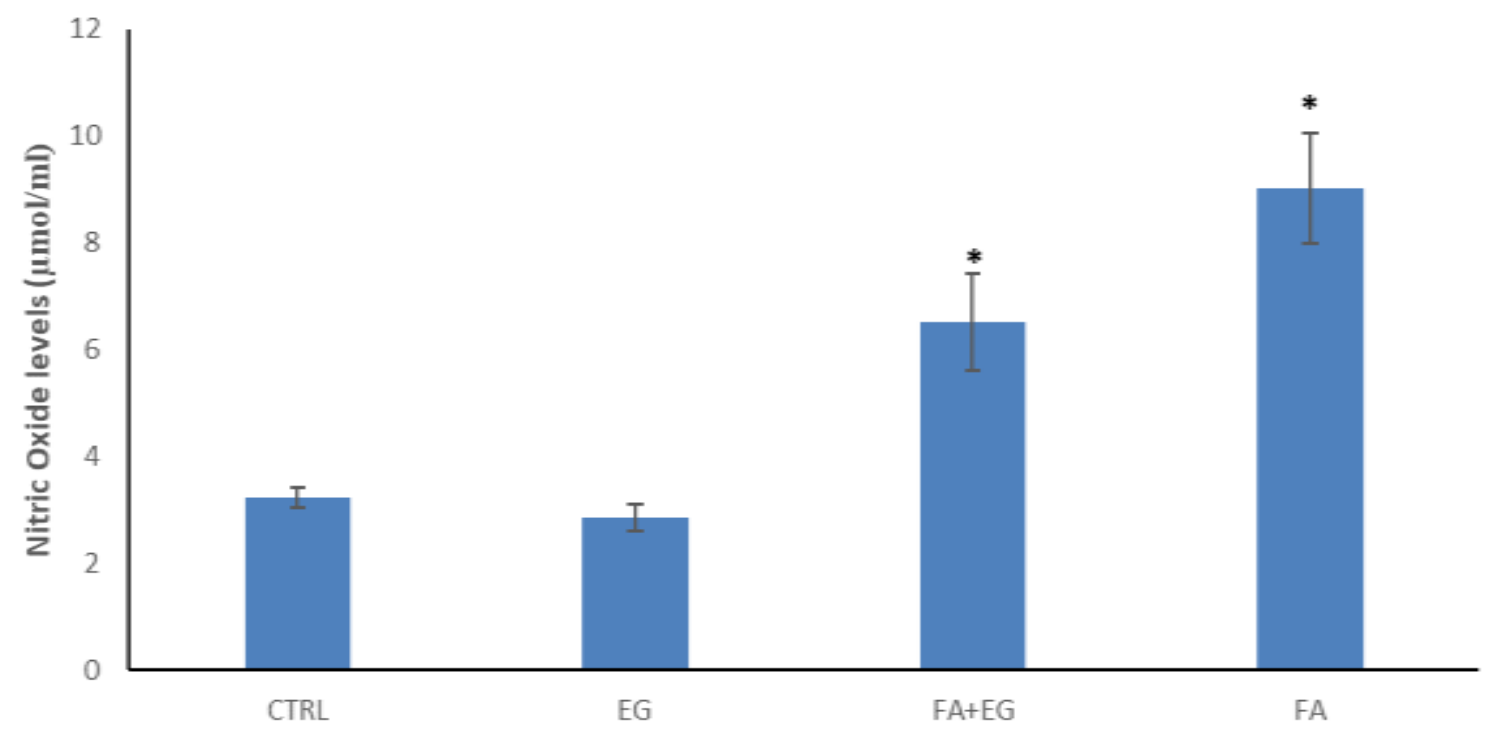

Figure 5: Effect of Eugenol on Nitric oxide levels following administration of FA $\mathrm{n}=6$; mean \pm SEM One way Turkey’s post-hoc test: * $=\mathrm{p}<0.05$, when FA+EG is compared to FA group. 
Figure 6 shows the effect eugenol on Malondialdehyde (MDA) activity in Wistar rats following administration of FA. This result shows a significant $(\mathrm{p}<0.05)$ increase in the activity of MDA in the group administered FA when compared to the control (CTRL). However co-administration of eugenol and formaldehyde (FA+EG) shows a significant reduction in the tissue level of MDA when compared to the FA treated group. In the group administered eugenol only, level of eugenol is not significant $(\mathrm{p}>0.05)$ when compared to the control (CTRL)

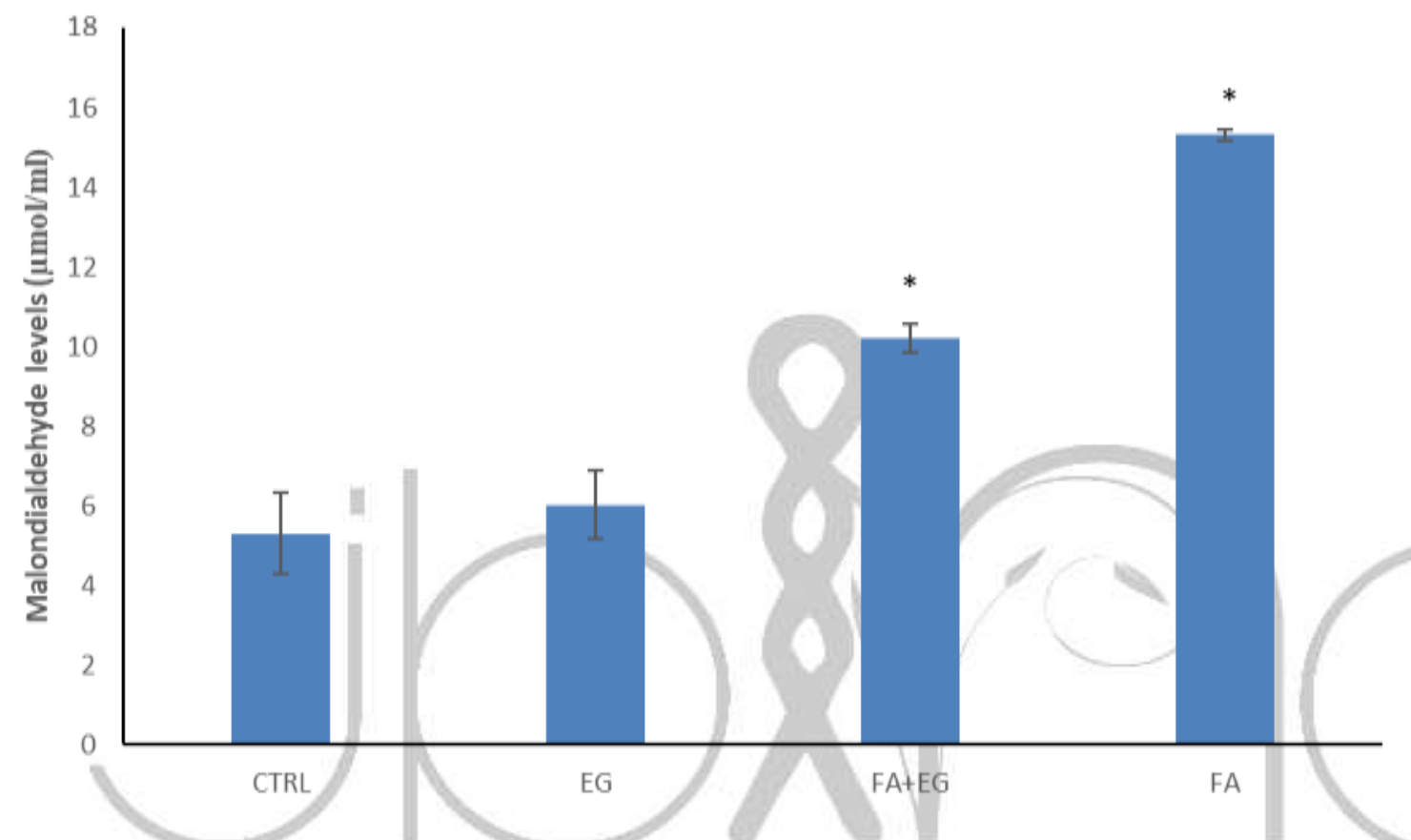

Figure 6: Effect of Eugenol on tissue level of Malondialdehyde following administration of FA $\mathrm{n}=6$; mean \pm SEM One way Turkey’s post-hoc test: * $=\mathrm{p}<0.05$, when FA+EG is compared to FA group.

\section{Discussion}

Liver is a vital organ and its highly specialized cells, hepatocytes, regulate a variety of biochemical reactions and functions. It plays pivotal role in detoxification of drugs, metabolites, and toxins. It has also many functions in digestion, plasma protein synthesis, hormone synthesis, and glucose and lipid homeostasis. Liver is a sine qua non for life, and there is no way to compensate for the absence of liver functions. Hence, we need hepatoprotective agents to ensure its functions. Formaldehyde is toxic for the liver. Its injection, ingestion, or inhalation may cause hepatotoxicity [19]. Formaldehyde acts on cellular compounds such as lipids, proteins, and nucleic acids. It forms cross linkages between proteins, between protein and single stranded DNA by linking of primary amino groups in proteins with other nearby nitrogen atoms in protein or DNA through a - $\mathrm{CH} 2$ - linkage [20]. These effects destroy the cell [20]. These effects destroy
jbino.com I Innovative Association 
structures and cause cellular dysfunctions. After ingestion, formaldehyde rapidly diffuses into many tissues like the brain, liver, testis, lung, and eyes. So, it is regarded as hepatotoxic, reprotoxic, genotoxic, and carcinogenic [22]. When formaldehyde is taken up, it quickly metabolized and forms methanol and formic acid. Formaldehyde dehydrogenase that needs glutathione as coenzyme is the main enzyme in this pathway. Glutathione plays crucial roles in detoxification of many hepatotoxic chemicals and in cell protection from oxidative injury.

The use of natural products in the prevention and management of various illnesses has prominently increased in the last few years [23]. The present study established the promising hepatoprotective potential of Eugenol in the liver of Wistar rat and as a result, preventing liver damage caused by exposure to FA. The hepatoprotective potential of eugenol against FA was investigated by determining ALT and AST. ALT is an important liver damage enzyme that catalyzes transamination reactions. The occurrence of conditions that can cause liver damage such as hepatitis, injury and cancer, will result in higher levels of this enzyme [21]. AST which is a biomarker of liver damage, are cytosolic and mitochondrial enzymes whose levels are usually increased in cases of chronic illness and necrosis due to loss of hepatocellular integrity. These enzymes are involved in the transfer of a-amino groups from alanine and aspartate to the a-keto group of ketoglutarate to form pyruvate and oxaloacetate, respectively [24]. As shown in figures 1 and 2, there is a significant increase $(p<0.05)$ in the levels of these enzymes in the group administered FA when compared to the control. However, treatment with $150 \mathrm{mg} / \mathrm{kg}$ eugenol significantly reduced the elevated levels, showing Figure 1 and 2.

When the body metabolism is impaired, an increase in the production of toxic molecules such as free radicals. Antioxidants, known as free radical scavengers, are needed to reduce or neutralize the free radical formation [25]. The hepatic destruction caused by FA causes oxidative stress and produces reactive oxygen species (ROS), as shown in the significant increase in MDA and NO, which are known to be oxidative stress markers, and also a decrease in GPx and SOD, which are antioxidant markers. These obseryations are accordance to Payani ef al an and Mesole ef al. [26, 15] who reported that $F A$ exposure significantly reduced the levels of enzymatic and nonenzymatic antioxidants. However coadministration of eugenol significantly increases the activities and levels of these antioxidant markers as reported by [15]. These results indicated that animals treated with Eugenol cause a significant increase in the levels of antioxidant enzymes. These results are in line with the reports of other researchers that allude to the fact that Eugenol has antioxidant activities both in vivo and in vitro [27-29]. These results indicated the hepatoprotective efficacy of Eugenol.

\section{Conclusion}

Exposure to FA resulted in elevated levels of AST, ALT and production of free radicals and hence elevated levels of MDA, NO and reduced activity of vital free radical 2021 January Edition | www.jbino.com | Innovative Association 
scavenging enzymes such as GPX and SOD within the liver. Co-administration of Eugenol and FA resulted in a reduced Levels of AST and ALT and reduced levels of MDA and NO and increased in the tissue activity of GPx and SOD.

\section{Conflict of Interest}

None was declared for this study

\section{Funding}

This Study was self-funded

\section{References}

Formalin Exposure: A Review of Known Health Hazards and the Role of Innovation in Improving Safety; Merit Medical Systems, Inc.: South Jordan, UT, USA, 2019.

Repetto, R.; Baliga, S.S. Pesticides and the immune system: The public health risks. Executive summary. Cent. Eur. J. Public Health 1996, 4, 263-265.

Ellenhorn, M.; Schonwald, G.; Ordog, J. Diagnosis and Treatment of Human Poisoning; Williams and Wikins: Los Angeles, CA, USA, 1997.

ATSDR. Toxicological Profile for Formaldehyde. In ATSDR's Toxicological Profiles; Agency for Toxic Substances and Diseases: Atlanta, GA, USA, 2002.

WHO. IARC Monographs on the Evaluation of Carcinogenic Risks to Humans; IARC: Lyon, France, 2010; Volume 93.

Cheng, G.; Shi, Y.; Sturla, S.J.; Jalas, J.R.; Mclntee, E.J.; Villalta, P.W.; Wang, M.;
Hecht, S.S. Reactions of formaldehyde plus acetaldehyde with deoxyguanosine and DNA: Formation of cyclic deoxyguanosine adducts and formaldehyde cross-links. Chem. Res. Toxicol. 2003, 16, 145-152.

Restani, P.; Restelli, A.R.; Galli, C.L. Formaldehyde hexamethylenetetramine as food additives: Chemical interactions and toxicology. Food Addit. Contam. 1992, 9, 597-605.

Teng, S.; Beard, K.; Pourahmad, J.; Moridani, M.; Easson, E.; Poon, R.; Brien, P.J.O. The formaldehyde metabolic detoxification enzyme systems and molecular cytotoxic mechanism in isolated rat hepatocytes. Chem. Biol. Interact. 2001, $132,285-296$.

Rumchev, K.B.; Spickett, J.T.; Bulsara, M.K.; Phillips, M.R.; Stick, S.M. Domestic exposure to formaldehyde significantly increases the risk of asthma in young children. Eur. Respir. J. 2002, 20, 403-408.

Nouh, W.G.; Selim, A.G. Toxopathological Studies on the Effect of Formalin and Copper Sulphate in Tilapia as A Commonly Used Disinfectant in Aquaculture. J. Appl. Environ. Biol. Sci. 2013, 3, 7-20.

Takahashi, M.; Hasegawa, R.; Furukawa, F.; Toyoda, K.; Sato, H.; Hayashi, Y. Effects of ethanol, potassium metabisulfite, formaldehyde and hydrogen peroxide on gastric carcinogenesis in rats after initiation with n-methyl-n0 -nitro-n-nitrosoguanidine. Jpn. J. Cancer Res. GANN 1986, 77, 118124.

2021 January Edition |www.jbino.com | Innovative Association 
Franklin, P.; Dingle, P.; Stick, S. Raised exhaled nitric oxide in healthy children is associated with domestic formaldehyde levels. Am. J. Respir. Crit. Care Med. 2000, 161, 1757-1759.

Gowri Shankar, N.L.; Manavalan, R.; Venkappayya, D.; David Raj, C. Hepatoprotective and antioxidant effects of Commiphora berryi (Arn) Engl bark extract against $\mathrm{CCl} 4$-induced oxidative damage in rats. Food Chem. Toxicol. 2008, 46, 3182-3185.

Kodavanti, P.R.S.; Joshi, U.M.; Young, R.A.; Meydrech, E.F.; Mehendale, H.M. Protection of hepatotoxic and lethal effects of $\mathrm{CCl} 4$ by partial hepatectomy. Toxicol. Pathol. 1989, 17, 494-505

Samuel B. Mesole Omachonu A. Okpanachi, Sunday S. Adebisi, Uthman A.Yusuf, Elvis T. Godam, Chanda G. Chisunka, Andrew Ivang, Animoku A. Abdulrazaq, and Tosin J. Kolawole (2020). Evaluation of the Neuroprotective Effects of Eugenol on Formaldehyde Induced Neurotoxicity in Wistar Rats, Nigerian Journal of Neuroscience; 11 (2): 62-70.2020.

Institute of Laboratory Animal Resources Committee on care and use of laboratory animals (2011). Guide for the care and use of laboratory animals. National Academies Press: Washington D.C. Accessed from https://www.nap.edu/catalog/12910/guid e-for-thecare-and-use-of-laboratoryanimals-eighth.
Rosebrough NJ, Farr AL, Randall RJ: Protein measurement with the Folin phenol reagent. J Biol Chem. 1951, 193: 265-275.

Mesole, S.B., Okpanachi, O.A., Yusuf, U.A., Lwiindi, L. and Ndhlovy, D. (2020) Apoptotic inducement of neuronal cells by aluminium chloride and the neuroprotective effect of eugenol in Wistar rats. Oxidative Medicine and Cellular Longetivity,

8425643. https://doi.org/10.1155/2020/8425643

19. Beall, J.R., and A.G. Ulsamer. 1984. Formaldehyde and hepatotoxicity: a review. Journal of Toxicology and Environmental Health 14: 1-21.

IARC Working Group on the Evaluation of Carcinogenic Risks to Humans, IARC MONOGRAPHS ON THE EVALUATION OF CARCINOGENIC RISKS TO HUMANS, WoOd Dust and Formaldehyde, Volume 62. 1995. Lyon

Kodavanti, P.R.S.; Joshi, U.M.; Young, R.A.; Meydrech, E.F.; Mehendale, H.M. Protection of hepatotoxic and lethal effects of $\mathrm{CCl} 4$ by partial hepatectomy. Toxicol. Pathol. 1989, 17, 494-505

IARC Working Group on the Evaluation of Carcinogenic Risks to Humans, IARC MONOGRAPHS ON THE EVALUATION OF CARCINOGENIC RISKS TO HUMANS, Formaldehyde, 2-Butoxyethanol and 1-tertButoxypropan-2-ol, Volume 88. 2004.

Oyebode, O.; Kandala, N.B.; Chilton, P.J.; Lilford, R.J. Use of traditional medicine in middle-income countries: A WHO-SAGE study. Health Policy Plan. 2016, 31, 984-991. 
Schiff, N.D.; Giacino, J.T.; Kalmar, K.; Victor, J.D.; Baker, K.; Gerber, M.; Fritz, B.; Eisenberg, B.; O'Connor, J.; Kobylarz, E.J.; et al. Behavioural improvements with thalamic stimulation after severe traumatic brain injury. Nature 2007, 448, 600-603.

Wang, Z.; Li, Z.; Ye, Y.; Xie, L.; Li, W. Oxidative stress and liver cancer: Etiology and therapeutic targets. Oxid. Med. Cell. Longev. 2016, 2016, 7891574.

Payani, S.; Mamatha, C.; Chandraprakash, C.; Bhaskar, M. Protective role of (Bronco-T) against formaldehyde induced antioxidant, oxidative and histopathological changes in lung of male Wistar rats. Toxicol. Rep. 2019, 6, 718-726

Zhao, W.; Jiang, X.; Deng, W.; Lai, Y.; WU, M.; Zhang, Z. Antioxidant activities of
Ganoderma lucidum polysaccharides and their role on DNA damage in mice induced by cobalt-60 gamma-irradiation. Food Chem. Toxicol. 2012, 50, 303-309. [CrossRef] [PubMed]

Hsieh, T.C.; WU, J.M. Suppression of proliferation and oxidative stress by extracts of Ganoderma lucidum in the ovarian cancer cell line OVCAR-3. Int. J. Mol. Med. 2011, 28, 1065-1069. [CrossRef] [PubMed]

Sohretoglu, D.; Huang, S. Ganoderma lucidum Polysaccharides as An Anticancer Agent. Anticancer Agents Med. Chem. 2018, 18, 667-674.

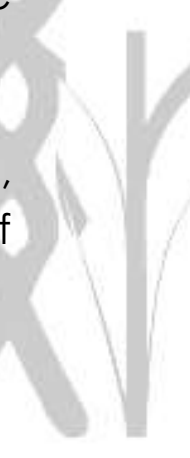

